\title{
A study to find impact of work duration on health in sugarcane factory workers.
}

\author{
Pratik V Pawar ${ }^{1}$, Pranjali Gosavi2 ${ }^{*}$, G Varadharajulu ${ }^{3}$, Amrutkuvar Jadhav ${ }^{4}$, Brinda Patel ${ }^{1}$ \\ ${ }^{1}$ Department of Physiotherapy, Krishna Institute of Medical Sciences, India \\ ${ }^{2}$ Department of Community Health Sciences, Krishna Institute of Medical Sciences, India \\ ${ }^{3}$ Department of Neurosciences, Krishna Institute of Medical Sciences, India \\ ${ }^{4}$ Department of Musculoskeletal Sciences, Krishna Institute of Medical Sciences, India
}

\begin{abstract}
Objectives: The objective of the study was as follows: To determine impact of work duration on musculoskeletal disorders in sugarcane factory workers.

Methods: Ethical clearance was obtained from the institutional ethical committee. A total of 74 sugarcane factory workers were assessed and all were included in this study based on inclusion criteria, Informed consent was taken and the workers were explained how their bad working conditions lead to musculoskeletal disorders and they were explained that this study helped us to find minimum duration which lead to musculoskeletal disorders and the data was collected using occupational health and safety standard questionnaire and Nordic musculoskeletal disorder questionnaire.

Results: This study found that duration for development of minimum complaints is within 1-5 years.

Conclusion: We found that average duration for development of minimum complaints start appearing within 1-5 years' work experience (1-1825 days) but maximum musculoskeletal disorders in sugarcane factory workers occur after a duration of 16-20 years (5476-7300 days) of work experience.

The musculoskeletal disorders which appears with minimum duration of 1-5 years initiates with neck pain followed by low back pain. The musculoskeletal disorders which occurs after maximum duration of work are neck pain, low back pain which increases with increased duration of work and with increased duration it leads to gradually increased complaints like shoulder pain, elbow pain, upper back pain, hip pain, knee pain and ankle pain.
\end{abstract}

Keywords: Impact, Work duration, Health, Musculoskeletal disorders, Sugarcane factory workers.

Abbreviations: RSI: Repetitive Strain Injury; MSDs: Musculoskeletal Disorders; OA: Osteoarthritis.

\section{Introduction}

The largest producer of sugarcane in the world is Brazil followed by India, China and Thailand. Sugar industry is one of the important agro-based industries not only in India but also in the world which directly contributes creating employment, income and social developments in the rural areas of the country. In India, there are 167 sugar factories. Both skilled and unskilled workers from rural areas are engaged in this sector. These workers are at high risk. Most of the sugar mills have poor occupational health and safety measures, inadequate policies and infrastructure to meet the health hazards. Hence the workers are exposed to workplace accidents, repetitive strain injury (RSI) and musculoskeletal disorders (MSDs) in neck, upper back, lower back and arms due to continuous movements [1].

Worksite analysis is done to identify existing hazards and conditions which contribute to ergonomic risks. It includes identifying low risk and light duty jobs which should be shared with and applied by health care officials when injured employees are being reassigned to work.

Work place is an important source for both demands and pressures which causes stress and structural and social response which helps to counteract stress. These factors may lead to health hazards. Intrinsic factors of work related stress include long hours of continuous work, work overload, time pressure, difficult tasks, lack of variety and poor physical work conditions (space, temperature and light) [1], while extrinsic 
factors include incorrect equipment, environmental factors, poor relations with colleagues and improper clothing and footwear.

Workplaces which have good communication, respectful relations and good and organised system of work help recognise and manage work stress and it tends to get good results in achieving productive work.

Occupational Health and safety at work is important in public health which requires workers and employees to adhere to safety guidelines to improve safety of work environment [2].

\section{Occupational hazard is of 2 types}

1. Health hazard: When worker suffers from illness due to hazard.

2. Safety hazard: When hazard physically injures worker.

Occupational health hazards are seen in various industries. $87.1 \%$ workers of sugar factories were having musculoskeletal disorders due to bad working conditions, bad lifting positions and lifting heavy loads. In textile industries, there is improper material handling, improper knowledge about machine due to lack of training and unsafe conditions. There is maximum number of injuries for hand/fingers followed by back/spine in textile industries [3].

Various injuries from material handling lead to Carpal tunnel syndrome, tendinitis, lower back pain, shoulder pain, and OA of knees due to heavy lifting and moving heavy cloth rolls. Work stress continuously due to badly designed shift work, work overload, poorly managed shift schedules, continuous exposure to harmful substances, high level of time pressure leads to increasing stress which leads to work related health hazards (Figure 1) [4].
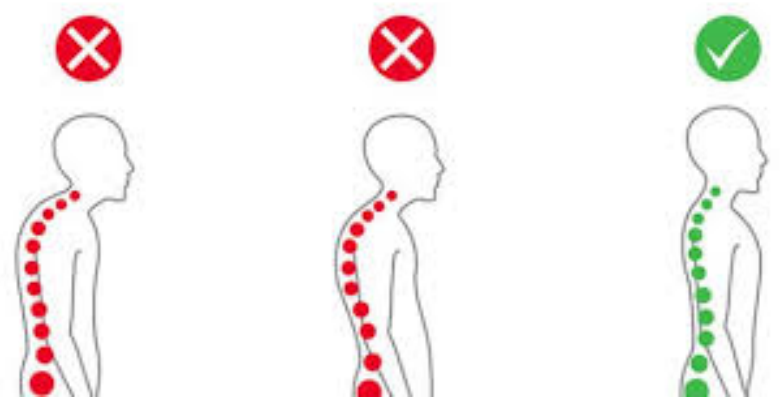

Figure 1. Work related health hazards.

As most workstations are not designed according to principles of ergonomics thus it leads to various work related musculoskeletal disorders which have significant influence on labourers and industries and it is the most important problem. Work conditions at present are very poor which results in bad posture. Musculoskeletal disorders are injuries and illness of different body parts used during working. Symptoms of work related MSDs in different job in awkward posture are very high irrespective of tasks [5-8].
The risk of MSDS among workers with acceptable working postures and enhanced productivity by using minimum resources [9].

This study was steered to determine the impact of work duration on musculoskeletal disorders in sugarcane factory workers. It is assumed that the result of this study is suitable for planning, designing and implementing principles of ergonomics in industry workplace to reduce work related MSDs [10-12].

\section{Methods}

Ethical clearance was obtained from the institutional ethical committee. A total of 74 sugarcane factory workers were assessed and all were included in this study based on inclusion criteria, Informed consent was taken and the workers were explained how their bad working conditions lead to musculoskeletal disorders and they were explained that this study helped us to find minimum duration which lead to musculoskeletal disorders and the data was collected using occupational health and safety standard questionnaire and Nordic musculoskeletal disorder questionnaire.

\section{Sampling method}

Cluster Sampling method: The study included assessment of sugarcane factory workers and they were screened using occupational health and safety standard questionnaire and Nordic musculoskeletal disorder questionnaire.

\section{Results}

Primary outcomes used for the result were occupational health and safety standard questionnaire and Nordic musculoskeletal disorder questionnaire (Figure 2).

\section{Gender distribution in the study}

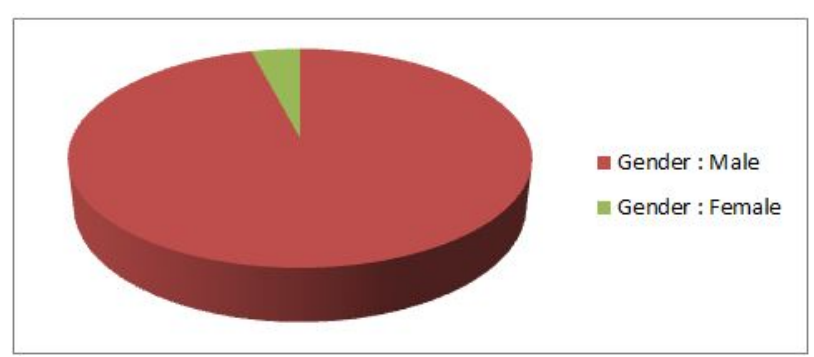

Figure 2. The pie diagram represents that out of 74 subjects, 71 males and 3 females have participated in this study.

\section{Age}

The age group included in this study is $30-60$ years. The Table 1 shows that minimum age group in the study is 31 years and maximum is 60 years. The mean of the age group is 48.432 years and standard deviation is 8.329. Table 2 represents minimum and maximum score of BMI. 
Table 1. The age group included in this study is 30-60 years.

\begin{tabular}{llll}
\hline Minimum & Maximum & Mean & Standard deviation \\
\hline 31 & 60 & 48.432 & 8.329 \\
\hline
\end{tabular}

Table 2. Table showing minimum and maximum score of BMI.

\begin{tabular}{llll}
\hline Minimum & Maximum & Mean & Standard deviation \\
\hline 16 & 34 & 24.189 & 3.564 \\
\hline
\end{tabular}

Table 3 distributes the study population in underweight, normal, overweight and obese categories along with gender distribution.

Table 3. BMI score.

\begin{tabular}{lllll}
\hline BMI Score & Frequency & Percentage & Male & Female \\
\hline$<18.50$ (underweight) & 2 & 3 & 2 & 0 \\
\hline $18.50-24.99$ (normal) & 50 & 68 & 48 & 2 \\
\hline $25-29.99$ (overweight) & 17 & 23 & 16 & 1 \\
\hline$>30$ (obese) & 5 & 6 & 5 & 0 \\
\hline
\end{tabular}

\section{Chief complaint}

Figure 3 clarifies that the most common chief complaint is neck pain with prevalence of $37 \%$ followed by LBP with prevalence of $15 \%$.

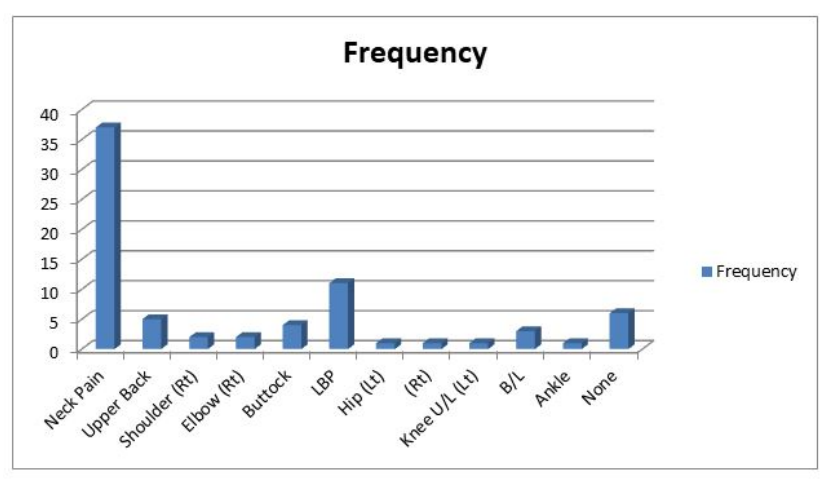

Figure 3. Represents various chief complaints and it's frequency along with gender distribution.

\section{Duration of chief complaint}

Table 4 shows minimum duration and maximum duration of chief complaint along with its mean and SD.

\section{Duration since worker is working in industry}

Table 5 represents minimum, maximum, mean and SD of duration since worker is working in industry.

Table 4. Minimum duration and maximum duration of chief complaint along with its mean and SD.

\begin{tabular}{llll}
\hline Minimum & Maximum & Mean & Standard deviation \\
\hline 0 & 9125 & 1253.56 & 1826.3 \\
\hline
\end{tabular}

Table 5. Minimum, maximum, mean and SD of duration since worker is working in industry.

\begin{tabular}{llll}
\hline Minimum & Maximum & Mean & Standard deviation \\
\hline 1095 & 16060 & 8404.86 & 4106 \\
\hline
\end{tabular}

\section{Year wise distribution of duration since worker is working in industry along with chief complaint}

Table 6 shows that most common chief complaint is neck pain followed by LBP and it states that neck pain is common since minimum duration of working and its prevalence increases with increased duration of work. Average duration for development of maximum musculoskeletal disorders in sugarcane factory workers is $16-20$ years (5476-7300 days) but minimum complaints start appearing within a duration of 1-5 years (1-1825 days).

Even low back pain increases with increased duration of work and with increased duration it leads to gradually increased complaints like shoulder pain, elbow pain, upper back pain, hip pain, knee pain and ankle pain.

\section{Discussion}

This study "A study to find impact of work duration on health in sugarcane factory workers" was conducted to find the impact of work duration on musculoskeletal disorders in sugarcane factory workers. As prevalence of workers who suffer from occupational health hazards is $86.4 \%$. Occupational health is an important aspect of public health and safety measure. There is no proper evidence of duration of work related physical stress to cause occupational health hazard. So, it is necessary to find impact of work duration on health in sugarcane factory workers.

The aim of the study is to find impact of work duration on health in sugarcane factory workers. The objective was to determine to find impact of work duration on musculoskeletal disorders in sugarcane factory workers.

The study was conducted with 74 subjects. Subjects were selected according to inclusion and exclusion criteria. Inclusion criteria was sugar factory workers, age group 30-60 years and both male and females. Exclusion criteria included other 
workers than sugarcane factory workers and workers suffering from cardiovascular diseases. In previous studies, prevalence of occupational hazards was $86.4 \%$ and now in this study it increased to $91.89 \%$.

Table 6. Indicates the duration since worker is working in industry and duration for development of each chief complaint.

\begin{tabular}{|c|c|c|c|}
\hline Duration since worker is working in industry & Frequency & Percentage & Chief complaint \\
\hline $1-5$ years ( $1-1825$ days) & 2 & $3 \%$ & $\begin{array}{l}\text { Neck pain - } 1 \\
\text { LBP- } 1\end{array}$ \\
\hline $6-10$ years ( $1826-3650$ days) & 10 & $14 \%$ & $\begin{array}{l}\text { Neck pain - } 9 \\
\text { LBP- } 1\end{array}$ \\
\hline $11-15$ years ( $3651-5475$ days) & 12 & $16 \%$ & $\begin{array}{l}\text { Neck pain - } 2 \\
\text { Rt shoulder pain - } 1 \\
\text { Upper back pain-2 } \\
\text { Buttock pain -2 } \\
\text { Ankle pain - } 1 \\
\text { None - } 4\end{array}$ \\
\hline $16-20$ years (5476-7300 days) & 15 & $20 \%$ & $\begin{array}{l}\text { Neck pain - } 9 \\
\text { Upper back - } 1 \\
\text { Rt elbow- } 1 \\
\text { Left hip- } 1 \\
\text { Left knee- } 1 \\
\text { LBP- } 1 \\
\text { Buttock pain - } 1\end{array}$ \\
\hline $\begin{array}{l}21-25 \text { years } \\
(7301-9125 \text { days })\end{array}$ & 4 & $5 \%$ & $\begin{array}{l}\text { Neck pain - } 3 \\
\text { Buttock pain - } 1\end{array}$ \\
\hline $26-30$ years ( $9126-10800$ days ) & 4 & $5 \%$ & $\begin{array}{l}\text { Upper back pain - } 2 \\
\text { B/L knee pain- } 1 \\
\text { None }-1\end{array}$ \\
\hline $31-35$ years (10801-12600 days ) & 8 & $11 \%$ & $\begin{array}{l}\text { Neck pain }-4 \\
\text { LBP- } 3 \\
\text { Rt Shoulder pain - } 1\end{array}$ \\
\hline $36-40$ years (12601-14400 days ) & 11 & $15 \%$ & $\begin{array}{l}\text { B/L knee pain- } 2 \\
\text { Neck pain }-4 \\
\text { LBP - } 2 \\
\text { Rt elbow pain -1 } \\
\text { Rt hip pain - } 1 \\
\text { None- } 1\end{array}$ \\
\hline $41-45$ years $(14401-16200)$ & 8 & $11 \%$ & $\begin{array}{l}\text { Neck pain }-4 \\
\text { LBP }-3 \\
\text { Rt hip pain }-1\end{array}$ \\
\hline
\end{tabular}

The most common chief complaint is neck pain followed by LBP and it states that neck pain is common since minimum duration of working and its prevalence increases with increased duration of work. Average duration for development of maximum musculoskeletal disorders in sugarcane factory workers is 16-20 years work experience (5476-7300 days) due to their bad working posture and improper handling habits for prolonged duration of working in sugarcane factories. Minimum complaints started appearing due to comparatively less duration of work in people with duration of 1-5 years work experience (1-1825 days).
In this study, 37 people suffered from neck pain, 5 suffered from upper back pain, 2 had right shoulder pain, 2 had right elbow pain, 4 people suffered from buttock pain, 11 people suffered from low back pain, 1 suffered from left hip pain, 1 suffered from right hip pain, 1 suffered from left knee pain, 3 suffered from B/L knee pain, 1 suffered from ankle pain and 6 had no complaints.

The musculoskeletal disorders in sugarcane factory workers have developed mostly due to high ergonomic risk as they have poor working posture and improper handling techniques. 
Even low back pain increases with increased duration of work and with increased duration it leads to gradually increased complaints like shoulder pain, elbow pain, upper back pain, hip pain, knee pain and ankle pain.

\section{Conclusion}

We found that average duration for development of minimum complaints start appearing within 1-5 years work experience (1-1825 days) but maximum musculoskeletal disorders in sugarcane factory workers occur after duration of 16-20 years (5476-7300 days) of work experience.

The musculoskeletal disorders which appears with minimum duration of 1-5 years initiates with neck pain followed by low back pain. The musculoskeletal disorders which occurs after maximum duration of work are neck pain, low back pain which increases with increased duration of work and with increased duration it leads to gradually increased complaints like shoulder pain, elbow pain, upper back pain, hip pain, knee pain and ankle pain.

\section{Acknowledgement}

We would like to acknowledge the guidance and support of Brinda Patel and Soel Gaikwad from faculty of physiotherapy.

\section{Authors' Contributions}

Pratik V Pawar conducted literature review for this manuscript, developed introduction section of the manuscript together with the discussion of the study findings, collected data, and analysed the data. Pranjali Gosavi provided the description of the background information and participated in preparation of the manuscript.

\section{References}

1. Michie S. Causes and management of stress at work. Occup Environ Med 2002; 59:67-72.

2. Mbonigaba E. To assess the prevalence of occupational health related risks and use of safety measures among employees in Bralirwa processing industries in Rwanda. Occup Med Health Aff 2015; 3:1-5.

3. Fatima SA, Shahid I. Isra Shahid Study of occupational health and safety conditions of a sugar mill in Pakistan. J Bio Env Sci 2017; 11:97-104.
4. Babel S, Tiwari M. Occupational health hazards in textiles industry. AJHS 2014; 9:267-271.

5. Schulte AP, Pandalal S, Wulsin V, Chun H. Interaction of occupational and personal risk factors in workforce health and safety. Am J Public Health 2012; 102:434-448.

6. Senthil A, Anandh B, Jayachandran P, Thangavel G, Josephin D, Yamini R, Kalpana B. Perception and prevalence of work related health hazards among health care workers in public health facilities in Southern India. Int J Occup Environ Health 2015; 21:74-81.

7. Biswas G, Bhattacharya A, Bhattacharya R. A review on the occupational health of sugarcane workers. IJBMR 2016; 7 .

8. Phoolchund HN. Aspects of occupational health in the sugarcane industry. Occupational Medicine 1991; 41:133-136.

9. Ayub Y, Shah ZA. Assessment of work related musculoskeletal disorders in manufacturing industry. J Ergonomics 2018; 8:1-5.

10. Bigoniya P, Shukla A, Singh CS. A survey on occupational health status of gardeners in Bhopal, India Indian J Community Med 2010; 35:487-490.

11. Descatha A, Roquelaure Y, Chastang JF, Evanoff B, Melchior M, Mariot C, Ha C, Imbernon E, Goldberg M, Leclerc A. Validity of Nordic-style questionnaires in the surveillance of upper-limb work-related musculoskeletal disorders. Scand J Work Environ Health 2007; 33:58-65.

12. Iti JL, Nigudi SR, Reddy S. Assessment of musculoskeletal disorders by standardized Nordic questionnaire among computer enginnering students and teaching staff of Gulbarga city. IJCMPH 2016; 3.

\section{*Correspondence to}

Pranjali Gosavi

Department of Community Health Sciences

Krishna Institute of Medical Sciences

India 